\title{
Introduction on Design of Enterprise University System Based on Functional Perspectives
}

\author{
Keying Chen \\ School of Business Administration, South China University of Technology, Guangzhou, China \\ Email: coin1227@163.com
}

How to cite this paper: Chen, K.Y. (2019) Introduction on Design of Enterprise University System Based on Functional Perspectives American Journal of Industrial and Business Management, 9, 11-20. https://doi.org/10.4236/ajibm.2019.91002

Received: December 12, 2018

Accepted: January 4, 2019

Published: January 7, 2019

Copyright $\odot 2019$ by author(s) and Scientific Research Publishing Inc. This work is licensed under the Creative Commons Attribution International License (CC BY 4.0).

http://creativecommons.org/licenses/by/4.0/

(c) (i) Open Access

\begin{abstract}
This paper tries to explore the general ways and methods in designing enterprise universities system from the four functions of enterprise universities, strategic promotion, personnel training, knowledge management and resource integration, so as to provide more directions and paths for the future development of enterprise universities. Rapid development and rapid product iteration have become the current development status of all walks of life. In this context, the cultivation of talents has been paid more and more attention by business managers. Many enterprises begin to think about the significance of employee training and talent development. Enterprise universities, as important carriers of enterprise learning, focus on strategies and serve enterprises. Compared with traditional enterprise training in the past, they are more strategic, integrated and autonomous. Through their unique operation modes and more systematic ways of personnel training, they are favored by more and more Chinese enterprises.
\end{abstract}

\section{Keywords}

Enterprise Universities, Functional Perspectives, System Design, Cultivation of Talents

\section{Introduction}

At present, the competition between enterprises has changed from simple organizational performance competition to more competitive talent competition. Enterprises are more and more aware of the importance of excellent talents for the development of enterprises. For enterprises, the most cost-effective way to obtain excellent talents is to train potential talents systematically to meet the needs of market development and the development prospects of enterprises. Therefore, the new organizational form of enterprise universities, which inte- 
grates enterprise strategy and talent training, emerges as the times require. However, some managers fail to grasp the differences between Enterprise Universities and traditional training functional departments. After the establishment of enterprise universities, they still use the traditional design system of training functional departments to plan enterprise universities. This ambiguity of concept and function directly leads to the name of enterprise universities not being true and becoming mere formalities. At the same time, it also causes the waste of enterprise resources. Therefore, it is urgent to clarify the concept definition, functions and characteristics of enterprise universities, to design proper systems for the enterprise universities.

\section{Literature Review}

\subsection{Human Capital Theory}

At present, the academia defines the concept of human capital mainly from two perspectives. One is from the perspective of academic development. The theory of human capital from this perspective focuses more on the study of capital. Schultz, the iconic figure of human capital, defines it as "the formation of knowledge and experience that can be measured in monetary form through human investment" [1]. The other is to define human capital from the perspective of historical development, focusing more on the importance of human capital, which is defined by Salo as "individual production technology, ability and knowledge" [2].

On the basis of the above definition of human capital, the author defines human capital as a human factor embodied in or hidden in the process of labor that can improve labor output and promote economic growth. This factor has the characteristics of privatization, increasing marginal income, timeliness and accumulation, heterogeneity and creativity, invisibility and incalculability. These characteristics provide the basis for the operation of enterprise universities and the return of education investment, which also reminds enterprise universities to pay attention to the return rate in talent cultivation.

\subsection{Learning Organization Theory}

In the 1990s, Dr. Peter Senge pointed out that "the most successful enterprise in the 1990s will be a learning organization, because the only lasting advantage in the future is the ability to learn faster than your competitors" [3]. Therefore, the real vitality of the enterprise is good at learning, and the growth process of the enterprise is a continuous learning process. Chen Guoquan, a Chinese scholar, put forward the definition of learning organization in his research: "Learning organization refers to an organization that can consciously, systematically and continuously create, accumulate and utilize knowledge resources and strive to change or redesign itself to adapt to the changing internal and external environment so as to maintain sustainable competitive advantage" [4]. Learning organizations are permeated with learning atmosphere suitable for communication 
among employees, so it is easy to make learning a habit. As an important carrier for enterprises to create learning organizations, the enterprise university is an organizational learning system, which has the characteristics of openness and innovation. It can enable employees to share, transfer and innovate enterprise knowledge resources, and fundamentally enhance the core competitiveness of enterprises [5].

\section{The Definition of Enterprise University}

The concept of enterprise universities was first adopted by Walt Disney in the 1950s, but there is no unified understanding of the concept of "enterprise universities" in academic or business circles [6]. Generally speaking, the concept definition of enterprise university can be divided into three categories: From the perspective of the status of enterprise university in the whole social education system; From the perspective of the difference between enterprise university and traditional training functional departments; From the perspective of the operation mode of enterprise university. From the above definition dimension, we can see that enterprise universities are different from traditional enterprise training departments, have unique operation modes, and have a certain position in the whole social education system of enterprise education and training institutions.

\section{The Characteristics of Enterprise University}

With the popularization of the concept of enterprise university and its concrete application in enterprise practice, more and more managers realize that enterprise university is not just a simple product of changing the name and renting a venue for traditional training functional departments, on the contrary, the establishment of enterprise university needs to be considered and positioned in terms of strategy, function and operation mode. Jenny C. Meister said that "the difference between Enterprise Universities and traditional training centers lies in the shift from 'one-off training activities' to a culture of continuous learning [7]." Compared with traditional enterprise training functional departments, enterprise universities have the following characteristics.

\subsection{Enterprise Universities Are Strategic}

Traditional enterprise training functional departments focus on problem solving, that is, training needs first, or training tasks first issued by superiors, and then to organize and implement training plans. From task reception to task completion, they are in a passive role. In addition, traditional enterprise training functional departments focus more on training work skills, that is, the promotion of current interests [8].

Enterprise universities, however, start from the development strategy of enterprises, keep up with the development direction of enterprises, consider and tap new training priorities from the perspective of enterprise talent demand, and develop new training courses. When the strategy of an enterprise changes, its 
course direction and resource allocation will also change accordingly [9].

\subsection{Enterprise Universities Are Integrated}

Traditionally, the training functional departments of enterprises classify the training courses and participants in the dimension of business departments. Even some enterprises choose different business departments to manage training projects by different leaders, which directly results in the dispersion of training resources and the waste of human and material resources within enterprises.

As the sole education and training center of the enterprise, the enterprise university has the most core and comprehensive training resources in the enterprise. It has a unified management system for all training projects and activities of the enterprise. By setting up different types of university courses, it can categorize the integrated information and teachers to meet the needs of different business departments. In this way, to a large extent, makes the training resources within the enterprise get the optimal allocation [10]. At the same time, through the training of employees, enterprise universities combine corporate culture, corporate brand and core technology to realize the internal integration of enterprise strategic resources and enhance the image and competitiveness of enterprises.

\subsection{Enterprise Universities Are Autonomous}

The autonomy of enterprise universities is mainly embodied in curriculum development, teacher management, business operation and so on. In the previous discussion on the strategic characteristics of enterprise universities, it is mentioned that the traditional training projects of enterprise training functional departments are mostly carried out from the perspective of passive acceptance of tasks, and are in a supporting position for business departments or enterprises.

From the strategic point of view, as an independent business unit operating in the enterprise, enterprise universities can independently develop courses and allocate teachers under the guidance of enterprise strategy, which is also the embodiment of enterprise strategy. The author found that there are two modes of operation of enterprise universities, one is mainly independent of the human resources department, which is on the same level with the human resources department, and the other is subordinate to the human resources department, but independent of other human resources modules.

\section{Functions of Enterprise University}

As a strategic enterprise education and training institution, enterprise universities are endowed with some other new functions closely related to the development of enterprises, besides the concept of talent cultivation advocated by traditional training functional departments. Yan Fen put forward that the core functions of enterprise universities are "education, training, development, learning and research" in the study of Oakang University in China [11]. Zhang Lin found 
that the functions of American enterprise universities can be summarized as "improving the knowledge management ability and adaptability of enterprises, promoting the sustainable development of enterprises, and helping enterprises integrate strategic resources to enhance their competitive advantages" [12]; Wu Feng proposed in his research on the development and trend of enterprise universities that "learning and talent training" is the primary function of enterprise universities, which provide learning conditions and opportunities for employees, thus creating economic value for enterprises, and at the same time, it can develop and inherit corporate culture. Enterprise universities can enhance employees' sense of corporate identity and enhance their sense of mission and loyalty to the enterprise [13].

Based on the introduction and research of the above literature, this paper summarizes the functions of enterprise universities as follows.

Strategic promotion. As a new mode of enterprise education, enterprise universities are founded by enterprises, originated from enterprises and rooted in enterprises [14]. Its primary mission is to serve enterprises, so the function of strategic is indispensable. Enterprise universities promote strategies and publicize corporate culture by taking all kinds of courses as carriers, realize the acceptance of high-rise buildings and establish corporate brand, at the same time, enable employees to get a sense of identity and belonging, establish emotional ties with enterprises, so as to enhance enterprise performance.

Talent training. As education and training departments, enterprise universities still have traditional training functions. The concept of talent training advocated by the enterprises should be based on the traditional simple and transient concept of talent training, and should promote more talent selection and predictability of talent training programs. It should be prior to business needs to train talents, cultivate high-potential talents suitable for enterprises and able to truly improve their performance. The important value of enterprise universities lies in the promotion of professional skills and comprehensive qualities through the selection and targeted training of talents, so as to enhance the adaptability, innovation ability and core competitiveness of enterprises.

Knowledge management. As an intensive learning organization within an enterprise, the students have different skills and different knowledge backgrounds. They communicate and learn from each other in the enterprise university. Their knowledge collides here, thus influencing each other to form new knowledge and internalize it [15]. Enterprise universities store and update knowledge in time for enterprises, transfer knowledge efficiently on the platform, realize the mutual transformation of explicit knowledge and tacit knowledge within enterprises, and implement the precipitation of enterprise knowledge. Therefore, enterprise universities have the function of knowledge management.

Resource integration. As the only centralized education and training institution in enterprises, enterprise universities need to collect all the training resources within the enterprise, carry out the most advanced and efficient training courses, and integrate the strategic resources such as culture, brand and tech- 
nology through employee participation in the training courses, so as to enhance the competitiveness of the enterprise.

\section{Design of Enterprise University System}

At present, the system research of the enterprise university mostly carries on the analysis and the design from the enterprise university's operation pattern, regards enterprise universities more as independent organizations from other departments of enterprise. Such system design method divides the relationship between enterprise universities and other business departments as well as functional departments. To a great extent, it reduces the realizability of university functions. Therefore, in order to better and more effectively realize the four functions of enterprise universities, the author tries to put forward the following methods and suggestions for the design of enterprise university system.

\subsection{Clear Enterprise Needs, Curriculum Development Design and Completion Evaluation}

The fundamental difference between enterprise universities and traditional training functional departments lies in the study of changes in the external environment of society and grasp direction of enterprise strategy. Therefore, enterprise universities should pay attention to the inheritance and landing of enterprise strategy in curriculum development design and completion evaluation.

Firstly, as the ultimate beneficiaries of talent training, the training objectives of enterprise universities should be closely related to the various indicators of talent demand of enterprises. Enterprise universities should clarify the roles of their strategic promoters. Based on the full interpretation of the enterprise strategy and the stage of enterprise operation and development, and taking the development needs of the trainees as a reference, the training tone and direction are determined to ensure the effectiveness of the whole training plan from the source.

Then, in the process of curriculum development and design, the enterprise university should have its own professional team of curriculum development and design. The team should pay attention to the consistency between enterprise strategy and the content of the curriculum developed. At the same time, it should also pay attention to the consistency between strategic needs and the way of curriculum development, that is, whether the time, place and mode of curriculum development are feasible or not, whether teaching methods used are efficient or not. With the development of electronic technology and Internet technology, enterprises can adopt more online teaching methods in the course teaching stage, which can make the whole training process flexible and also achieve effective supervision. At the same time, we should accurately grasp the project budget of curriculum development to ensure reasonable and effective curriculum development and design within the affordable scope of enterprises. Generally speaking, curriculum development and design need to be constantly adjusted according to the development direction of enterprise strategy in order 
to achieve the optimal allocation of resources in all aspects.

In the final step of training, enterprise universities should establish training evaluation database and determine the level of training evaluation according to the needs of enterprise strategic development, and determine strict and reasonable evaluation criteria. In the selection of evaluation methods, we should also pay attention to all-round and diversity. We should choose different time to interview or evaluate different employees or managers with different emphasis, so as to ensure the training effect and get training feedback, so as to ensure that training is effective.

\subsection{Establish the Selection Mechanism to Endow High Potential Talents}

Enterprise universities, as a channel for enterprises to train and transport outstanding talents, should pay special attention to the selection of training objects. Enterprise universities should be clear that their training resources are not inexhaustible, and the use of training resources should be appropriate in order to achieve the highest benefits. Therefore, enterprise universities should make it clear that their clients should not be all employees of the enterprise, but only the high-potential talents within the enterprise, because only the high-potential talents are the core force that can really promote the progress of the enterprise.

Enterprise universities should cooperate with the Human Resources Department in the selection of training objects. The former is responsible for the specific implementation of training and empowerment, while the latter is responsible for the selection of training objects by means of talent inventory and internal assessment. When the trainees complete the training courses in the enterprise university, they should be assigned to the business department and the human resources department to formulate the next growth path according to the specific system. After a period of practical business, they should repeat the previous selection flow when they are qualified for another training and selection through the position promotion assessment of the human resources department. At the same time, in the construction of enterprise learning atmosphere, enterprise universities should also pay attention to the construction of enterprise learning atmosphere as a whole, incline learning resources to high-potential talents, and encourage them to drive all employees to study independently and grow independently.

Enterprise universities cultivate and transport a batch of excellent talents for enterprises through the above cycle selection, cycle enabling mechanism of "Selection-Training-Practical-Re-Selection-Re-Training-Re-Practical" and the construction of the overall learning atmosphere of enterprises, so as to enhance the core competitiveness of enterprises.

\subsection{Establish Online Sharing Platform to Realize Enterprise Knowledge Sharing}

Compared with the traditional off-line teaching, off-line examinations, paper 
textbooks and other temporary training modes, the rapid development of the Internet provides more new possibilities for the training mode of enterprise universities. Enterprises can store, update, create and transfer knowledge by establishing their own independent online sharing platform, and the explicit knowledge and tacit knowledge can be well transformed into each other.

Enterprise universities input the data of each student into the database, establish the learning files of each student, track the learning dynamics of each student, promptly supervise the learning of the students, which facilitates the management of the whole training process. At the same time, all the teaching materials and the completion evaluation and other training items are placed in the database. According to their own needs, students can log on to the platform anytime and anywhere to view the content of the corresponding courses and complete the examination. They can also communicate and discuss online with other students who watch videos. In addition, by adding enterprise case base on the platform, employees are encouraged to upload and share cases worth learning and promoting in their work, so as to achieve rapid knowledge sharing.

\subsection{Build Enterprise Resource Pool to Realize All-Round Resource Integration}

Enterprise universities are to help enterprises solve problems, so it is very important to integrate the resources of enterprises. Enterprise universities need to integrate four resources: lecturer resources, business resources, student resources and external resources.

Lecturer resources: Enterprise university workers should keep close contact with enterprise managers, be able to accurately observe the changes of concerns in each period, take their concerns as a starting point, and seek solutions as a foothold to plan new training projects, which have been supported by managers. Where possible, managers are invited to participate in the teaching process of training, increase the gold content of training projects, and build momentum for training projects, so as to achieve good training response and training effect. In addition, for the business backbone of each department, enterprise universities should set up a selection and reward mechanism. On the basis of meeting the requirements, they should be encouraged to go to the lecture hall and teach professional knowledge to the students, so as to realize the inheritance and development of professional experience and spirit.

Business resources: Enterprise universities' training projects ultimately end up in business. Therefore, the incorporation of business personnel into the training project team is a powerful guarantee to ensure the effectiveness of training projects. Only the business department can really understand what the front-line business personnel need, what they want, and how to provide resources is the most effective. Workers in enterprise universities should always bear in mind that business departments are customers of Enterprise Universities and should treat business departments and business personnel with an attitude towards customers. 
Student resources: As a large group of participants in training projects, students should attach importance to the flow of resources among themselves. Enterprise universities should build platforms to achieve mutual assistance among students and answer questions and doubts. For example, regular "mutual assistance workshops" and "student exchange seminars" can be organized to promote exchanges between students; students at different occupational levels can also be formed into one-to-one teaching groups, point-to-point vocational skills counseling, advanced with intermediate, intermediate with grass-roots, level-to-level mutual assistance, layer-to-layer communication.

External resources: External resources here mainly refer to external training resources. Through learning, absorbing and adopting external training methods, introducing good external teachers, technology and so on, the quality of internal training projects can be improved.

\section{Conclusion}

To sum up, the enterprise university is developed from the traditional enterprise training functional department, so it has the basic elements of the traditional training functional department, but also has four functions of strategic promotion, personnel training, knowledge management and resource integration because of its strategic, integrated and autonomous characteristics. Enterprise university workers should start from these four functions and think about the enterprise university system suitable for the enterprise's own development from the dimensions of training demand analysis, training object selection, knowledge storage and sharing, and training resource database establishment. They should never talk about university without strategy and function. Only in this way can universities really promote the strategic development of enterprises and help enterprises to enhance their core competitiveness.

\section{Conflicts of Interest}

The author declares no conflicts of interest regarding the publication of this paper.

\section{References}

[1] Schultz, T.W. (2016) The Source of Increasing Compensation. Renmin University Press, Beijing.

[2] Chai, W.J. and Zhao, J. (2011) Review of Human Resources Literature. Modern Communication, No. 6, 27-28.

[3] Peter, S.G. (2003) The Fifth Discipline. Shanghai Sanlian Bookstore Publishing House, Shanghai.

[4] Chen, G.Q. (2002) Studies on the Process Model, Design Principles and Nature of Learning Organization. Chinese Journal of Management Science, No. 4, 86-94.

[5] Wang, J.J. (2017) Research on the Operating System of International Well-Known Enterprise Universities: A Case Study of HP Business School. M.B.A. Thesis, Zhejiang University of Technology, Hangzhou. 
[6] Zhao. J. (2018) Research on Enterprise University Transition Based on Organizational Development Theory. Technology Wind, No. 31, 226-227.

[7] Meister, J.C. (2005) Corporate Universities: Lessons in Building a World-Class Work Force. People's Posts and Telecommunications Publishing House, Beijing.

[8] Cen, M.Y. (2006) Enterprise University-The Key Strategy of Enterprises in the 21st Century. Tsinghua University Press, Beijing.

[9] Ma, L. (2009) Research on the Training Model of Talents in Enterprise Universities. M.A. Thesis, Lanzhou University, Lanzhou.

[10] Wang, S.Y. (2011) What Does an Enterprise University Do? The Function of an Enterprise University and Its Influence on Organizational Learning Ability. Economic Science Publishing House, Beijing.

[11] Yan, F. (2008) The Development, Problems and Countermeasures of Corporate University in China-Aokang University as An Example. Ph.D. Thesis, Shanghai Jiao Tong University, Shanghai.

[12] Zhang, L. (2008) American Enterprise University Research-Take Disney as an Example. M.A. Thesis, Central University for Nationalities, Beijing.

[13] Wu, F. (2012) Research on the Development and Trend of Corporate Universities. Research in Higher Education of Engineering, No. 4, 83-89.

[14] Liang, L.M. and Sang, X.M. (2012) Interpretation and Enlightenment of the Rise of Contemporary Enterprise Universities. Educational Research, No. 9, 79-85.

[15] Zhang, J. (2003) A Review of the Functions of Corporate Universities. Science Research Management, No. 4, 133-138. 